Population, Health and Nutrition Department, Human Resources Development and Operations Policy, The World Bank, 1818 H Street, NW, Washington, DC 20433, USA

H Barnum

\section{The economic burden of the global trade in tobacco}

\author{
Howard Barnum
}

This paper was presented at the 9th World Conference on Tobacco and Health, held on 10-14 October 1994 in Paris, France. The author is a senior economist at the World Bank. The methodology used to estimate the producer and consumer benefits and the economic costs of tobacco consumption is described in an internal World Bank document which may be obtained from the author ( $H$ Barnum, The economic costs and benefits of investing in tobacco, March 1993, 21 pp). An editorial commenting on this paper appears on page 295 of this issue of Tobacco Control. - ED

\begin{abstract}
It is well known that tobacco is bad for health. In fact, every ton of tobacco consumed results in approximately one death. What is not so well known is that tobacco is, globally, a net economic disaster as well. There are some benefits to consumers and producers in the form of immediate pleasure and profits that can be estimated from market data, but these market benefits are dwarfed by the cost of sickness and death caused by tobacco use.
\end{abstract}

Fortunately, there are highly costeffective policies available to use against tobacco. These policies include taxes, anti-tobacco legislation, information and education, and advertising bans. Cost analysis shows that these policies cost only a fraction per year of life saved compared to the treatment of tobaccocaused disease.

The World Bank has concluded that it does not make good economic sense to lend money for tobacco projects but it does make good sense to lend for antitobacco activities in health projects. Ministers of finance should take these economic facts into account and should support strong measures to control tobacco use in their countries.

(Tobacco Control 1994; 3: 358-361) many of you are from ministries of health or work in the health sector in developing countries and, by providing your governments with a focus on the link between health and tobacco, can bring about policies that will eventually save additional millions of lives. I would like to address this group in particular because I know that you face opposition not only from the tobacco trade lobby but also, in some cases, from your ministries of finance.

I intend to give you a message to convey to your ministers of finance. Tobacco is too great a problem to be left to the health sector alone. To obtain better national tobacco policies it is necessary to convince Ministers of Finance that controlling the consumption of tobacco is not only good for people's health but also an important policy for their countries' economic prospects.

\section{"The world tobacco market produces an annual global loss of US\$200 billion."}

The message I hope to convey is that tobacco use is globally an economic disaster as well as an enormous economic problem in individual countries. This is one economic problem that many countries in the developing world have avoided so far (for example, Africa, parts of Latin America, some Asian countries, and the Middle East), but it is coming. International tobacco companies have targetted the developing world to replace diminishing sales in Western Europe and North America. Fortunately, there are low-cost and effective policies to control tobacco use and, if implemented now, these policies can avoid the waste of billions of dollars in developing countries in the future.

My remarks can be divided into three sections. The first section gives some data on the global economic impact of tobacco use. The second gives a perspective on the current and possible future use of tobacco in developing countries, and the third section illustrates the cost-effectiveness of anti-tobacco policy.

Thus, the three sections state the magnitude of the problem globally, point out the danger for rapidly industrialising nations, and finally point out the economic practicality of addressing the problem.
Introduction

It is an honour and an extraordinary opportunity to speak to this conference. It is an honour because of the dedication with which you are working for better health in spite of the aggressive opposition mounted by those with a vested financial interest in world tobacco trade. It is an extraordinary opportunity because 
Table 1 Total world consumption of tobacco (thousands of tons - dry weight)

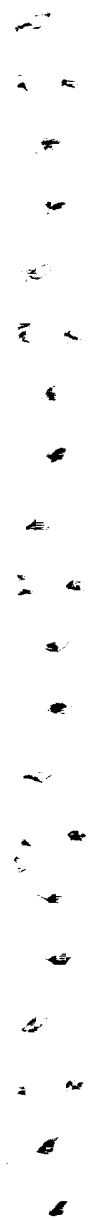

$-$

$:-$

\begin{tabular}{llll}
\hline Region & 1975 & 1985 & 1995 \\
\hline Developing & 2300 & 3700 & 5000 \\
Developed & 2400 & 2300 & 2300 \\
World & 4700 & 6000 & 7300 \\
\hline
\end{tabular}

Source: FAO

Table 2 Morbidity and mortality from 1000 tons of added tobacco consumption ${ }^{\star}$

\begin{tabular}{lcc}
\hline $\begin{array}{l}\text { Tobacco-induced } \\
\text { disease }\end{array}$ & Annual new cases & $\begin{array}{c}\text { Annual added } \\
\text { mortality }\end{array}$ \\
\hline Cancer & 230 & 200 \\
Cardiovascular & 440 & 330 \\
Cerebrovascular & 130 & 50 \\
COPD & 190 & 70 \\
Total & 990 & 650 \\
\hline
\end{tabular}

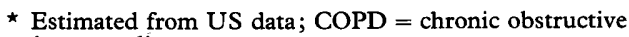
pulmonary disease

The global economic burden of tobacco GLOBAL CONSUMPTION

Turning to the first section, table 1 gives estimates from the Food and Agriculture Organisation (FAO) of the global consumption of tobacco for 1975 to 95 . Globally, consumption is expected to have increased by over $50 \%$ from 1975 to 95 . All of this increase comes in developing countries where consumption is to double. In developed countries consumption will actually have fallen from 1975 to 95 .

Mortality from global tobacco consumption The tobacco traded in the global market adds a net loss to world welfare. There is, of course, some short-term consumer satisfaction and added producer profits, but these benefits are dwarfed by the cost of morbidity and mortality caused by tobacco use.

Globally, tobacco caused 3 million deaths in the last year and is expected to cause 10 million deaths a year by 2025 . One in eight deaths in less developed countries is caused by tobacco, one in four in developed countries, and one in

Morbidity and mortality from 1000 added tons of consumption

To get some idea of the economic impact of these deaths and the associated illness, we estimated the global effect of adding 1000 tons of tobacco consumption. In a background paper prepared for the World Bank - to help examine the wisdom of our policy of not lending for tobacco-we estimated the producer and consumer benefits from tobacco consumption and compared them to the economic costs. six for the world as a whole.

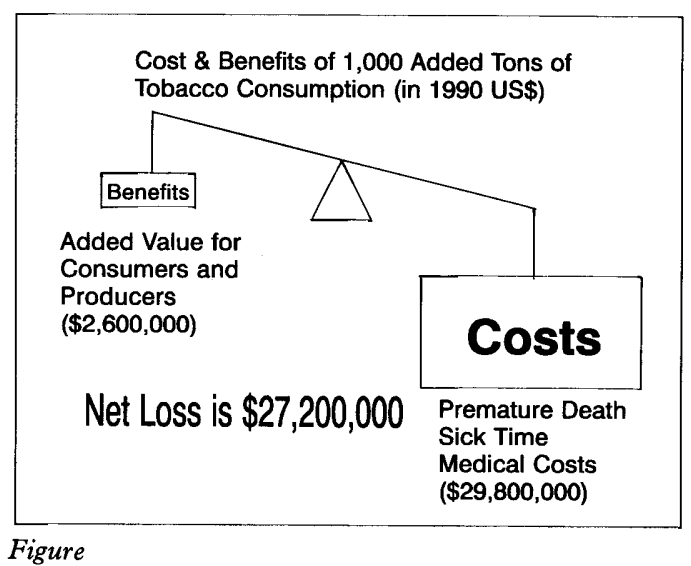

We have estimated, based on US Surgeon General data, that one ton of tobacco consumed causes an average of about 0.65 deaths, with an average lag of 25 to 30 years ${ }^{\star}$. Table 2 gives a breakdown of the number of deaths and new cases of illness from 1000 tons of added tobacco consumption. These are premature deaths and new cases distributed over a 30year period into the future.

\section{Costs and benefits of added consumption of 1000 tons}

With this breakdown by types of disease we can now look at the cost of illness from the 1000 tons of tobacco consumption and compare this with the benefits of consumption (table 3).

Value for consumers and producers Consumers derive immediate value, pleasure, from their consumption of tobacco. Producers also derive benefit, their profits, from the market for tobacco. There are economic methods for calculating the benefits of the consumption to producers and consumers. These involve an application of the estimated demand and supply responses characteristic of the market for tobacco. Using 1990 prices, we estimated that the added value for consumers and producers is US $\$ 2.6$ million.

Direct costs The medical burden of the consumption is obvious. Cancer, cardiovascular, cerebrovascular, and chronic obstructive pulmonary diseases are expensive to treat. The estimated direct costs of treatment are US $\$ 5.6$ million.

New estimates using recent data (Peto R, Lopez A, Boreham J, Thun M, Heath C Jr. Mortality from smoking in developed countries 1950-2000. Oxford: Oxford University Press, 1994) suggest that the number of deaths from one ton of tobacco consumption may be closer to 1.3 . If so, this would approximately double the estimated net economic costs of tobacco consumption.

Table 3 Costs and benefits from 1000 ton increase in tobacco consumption (in 1990 million US \$)

\begin{tabular}{lccc}
\hline Effect & Benefits & Costs & Net benefits \\
\hline Consumer \& producer benefits & 2.6 & & 2.6 \\
Premature death & & 13.2 & -13.2 \\
Indirect morbidity costs & & 11.0 & -11.0 \\
Direct morbidity costs & 2.6 & 5.6 & -5.6 \\
Total & & 29.8 & -27.2
\end{tabular}


Table 4 Selected cancer types as a percentage of all cancer by region (regional totals are $100 \%$ )

\begin{tabular}{lrr}
\hline Region & Mouth & Lung \\
\hline Sub-Saharan Africa & 5.3 & 5.8 \\
Middle East & 7.2 & 15.1 \\
India & 19.5 & 7.2 \\
Other Asia & 9.2 & 13.3 \\
South America & 5.1 & 8.7 \\
China & 3.4 & 12.0 \\
Former USSR and Eastern & 4.2 & 26.5 \\
Europe & & \\
Developed economies & 3.3 & 22.4 \\
World & 6.8 & 15.1 \\
\hline
\end{tabular}

Table 5 Rate of growth of tobacco consumption (percent per year)

\begin{tabular}{lrrr}
\hline Region & $1975-85$ & $1985-90$ & $1995-2000$ \\
\hline Developing & 4.8 & 3.4 & 2.7 \\
Developed & -0.4 & -0.2 & -0.0 \\
World & 2.4 & 2.1 & 1.9 \\
\hline
\end{tabular}

Source: FAO projections

Indirect costs In addition there are the socalled "indirect costs" of the economic value of the years of life lost to morbidity (US $\$ 11$ million) and premature mortality (US $\$ 13.2$ million).

Summing all of the benefits and costs, the 1000 added tons of consumption produces a global net loss of $\$ 27$ million (see figure). Obviously, from a global point of view, the production and consumption of tobacco is not a very good deal.

\section{Global net economic loss from tobacco consumption}

If we extrapolate the estimated net loss from 1000 tons to the 7 million tons produced in the world in 1990, we can get a very rough estimate of the global economic loss from tobacco. Using this approach, the world tobacco market produces an annual global loss of $\$ 200$ billion. About one third of this loss occurs in developing countries.

Socioeconomic change Urbanisation and access to mass media and education, at least initially, have acted to increase smoking in many countries. Increased income is, however, one of the most important factors. We have estimated that a $10 \%$ increase in per capita income can be expected to increase tobacco consumption by $7 \%$ in middle-income countries, and by more than $13 \%$ in low-income countries.

\section{Developing countries}

I will now consider the situation in developing countries.

\section{CURRENT SITUATION}

Until now, the developing world has felt only a small part of this economic loss, but the future could be very different. Lung cancer, although only one of the several health effects of tobacco, is a good indicator of the health burden from tobacco use, at least as far as smoking is concerned. This is because, in the absence of smoking, lung cancer is actually a minor and relatively rare disease.
Table 6 Key factors affecting growth in tobacco consumption in developing countries

\begin{tabular}{lc}
\hline Factor & Potential effect \\
\hline Population growth & + \\
Aging of population & + \\
Socioeconomic change: & ++ \\
$\quad$ Income & ++ \\
$\quad$ Urbanisation, & + \\
communication, education & depends on policy \\
Demand shift: & +++ (if no policy) \\
Advertising & depends on policy \\
Health information & depends on policy \\
\hline Regulation, norms & small effect;,++ large effect; +++ , very large effect.
\end{tabular}

Table 4 shows that in comparison with the rest of the world, lung cancer in the developing world accounts for a much smaller percentage of total cancer in men. The relative percentage for women is even smaller. If world tobacco companies have their way, however, this picture will change in the future. In fact, because current lung cancer is based on past consumption with a long lag, the recent increase in tobacco consumption that has already occurred in part of the developing world will cause an inevitable increase in illness in the future.

\section{PROJECTED GROWTH RATES}

The projected growth rate of tobacco consumption in developing countries is expected to be about $3 \%$ for $1995-2000$, barring new national policies that would thwart the current trend. This compares with no growth or decline for the developed world (table 5).

\section{FACTORS AFFECTING CHANGE IN TOBACCO} CONSUMPTION

It is useful to examine the factors behind the expected growth because the investigation may have some policy implications. The major factors that will affect change in tobacco consumption in developing countries are indicated in the chart below.

Demographic change The first two factors are the natural increase in population and the aging of the population. As children move upward through the population pyramid to reach adolescence and young adulthood - the age at which many people start smoking - the consumption of tobacco will increase.

Socioeconomic change Urbanisation and access to mass media and education, at least initially, have acted to increase smoking in many countries. Increased income is, however, one of the most important factors. We have estimated that a $10 \%$ increase in per capita income can be expected to increase tobacco consumption by $7 \%$ in middle-income countries, and by more than $13 \%$ in lowincome countries.

These two factors - demographic and socioeconomic change - are factors that governments do not control. Their effects are inexorable. There are, however, factors affecting change over which governments can exert considerable policy control. These include: 
Table 7 Cost per year of life gained from different health interventions (in a country with GDP=US\$ 2000)

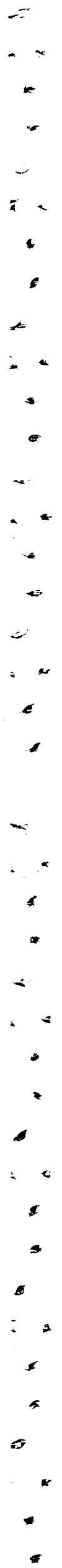

World Bank policy on tobacco In 1992, in recognition of the adverse effects of tobacco consumption on health, the World Bank articulated a formal policy on tobacco. The policy contains five main points.

- The World Bank's activities in the health sector-including sector work, policy dialogue, and lending-discourage the use of tobacco products.

- The World Bank does not lend directly for, invest in, or guarantee investments or loans for tobacco production, processing, or marketing. However, in the few countries that are heavily dependent on tobacco as a source of income and of foreign exchange earnings (for example, those where tobacco accounts for more than 10 percent of exports) and especially as a source of income for poor farmers and farmworkers, the World Bank treats the subject within the context of responding most effectively to these countries' development requirements. The World Bank seeks to help these countries diversify away from tobacco.

- To the extent practicable, the World Bank does not lend indirectly for tobacco production activities, although some indirect support of the tobacco economy may occur as an inseparable part of a project that has a broader set of objectives and outcomes (for example, rural roads).

- Unmanufactured and manufactured tobacco, tobacco-processing machinery and equipment, and related services are included on the negative list of imports in loan agreements and so cannot be included among imports financed under loans.

- Tobacco and tobacco-related producer or consumer imports may be exempt from borrowers' agreements with the Bank to liberalize trade and reduce tariff levels.

Source: World Bank. World development report 1993: Investing in health. Oxford: Oxford University Press, 1993; 89.

which had become de facto over the previous 10 years:

Bank operations include anti-tobacco activities in sector work, policy dialogue, and lending operations.

The Bank does not lend for tobacco production, processing, imports, or marketing, whether for domestic consumption or for export.

\section{Conclusion}

This, then, is the simple message. Tobacco consumption provides a net economic loss, and anti-tobacco policies are a cost-effective way to save lives and benefit the economy. I hope you are convinced and will convey this message to your ministers of finance. 